\title{
دور معايير التدقيق الدولية في تقليص فجوة التوقعات
}
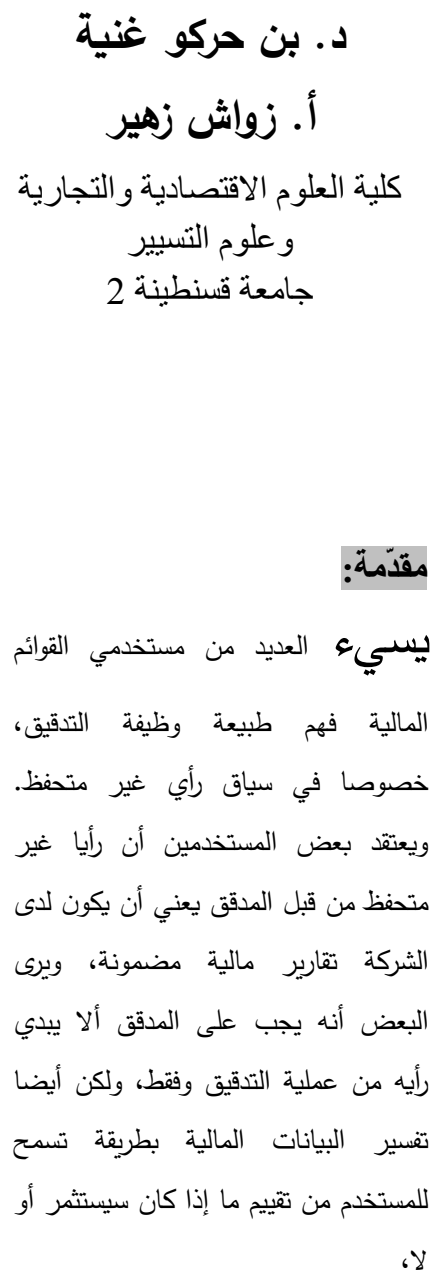

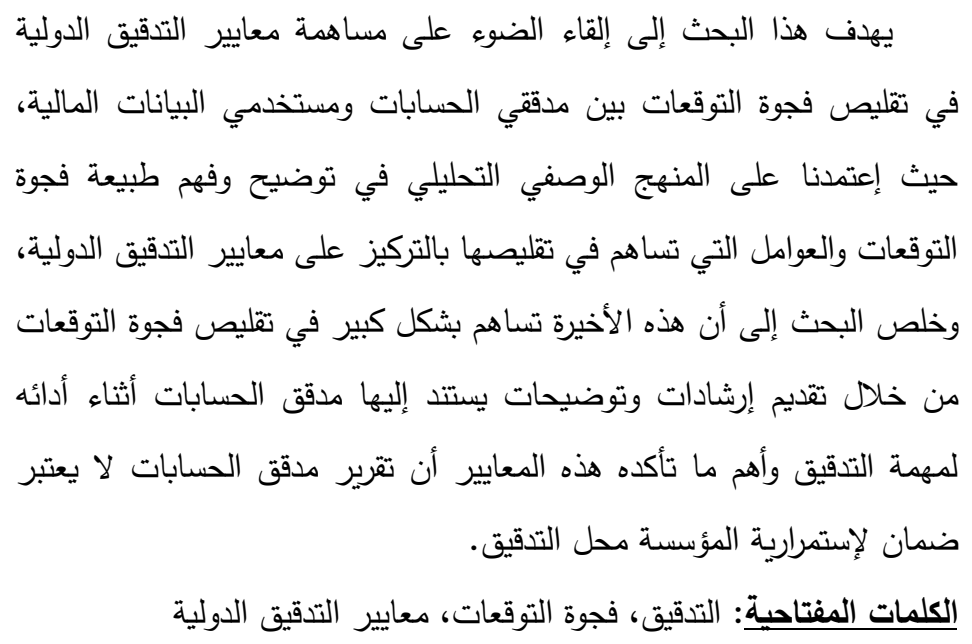

\section{Abstract}

This research aims at shedding light on the contribution of international auditing standards in reducing the expectations gap between auditors and users of financial statements. We relied on the analytical descriptive approach in clarifying and understanding the nature of the expectations gap and the factors that contibute to reducing it by focusing on international auditing standards. This research concludes that the international auditing standards has significantly contributed to redusing the expectations gap by providing guidance and clarifications on wich the auditors relied during theirwork, this standerds insist on the fact that the auditor's report is not a guarantee for the existence of the audited entity.

Keywords: audit, expectations gap, international auditing standards 
و هناك أيضا من المستخدمين من يتوقعون من المدققين أداء بعض إجراءوات التئن التدقيق أثناء أداء

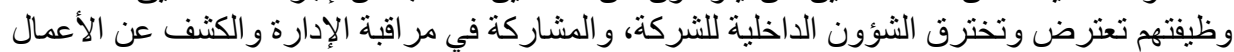
غير المشروعة أو الغش من جانبها.

ومن مثل هذه التوقعات العالية من جانب مستخدمي البيانات المالية تخلق فجوة بين نوقعات مدققي

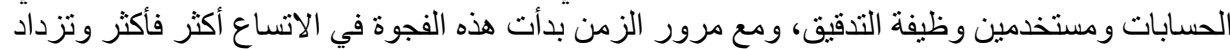

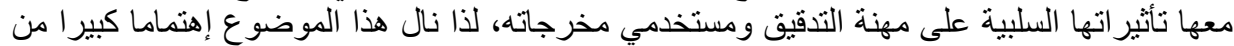

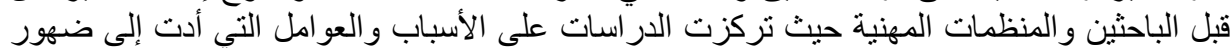

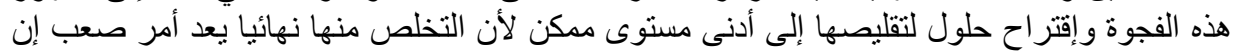

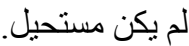

ويهذف هذا البحث إلى توضيح وفهم طبيعة فجوة التوقعات ونطاقات ودراسة العو امل التي نأثر

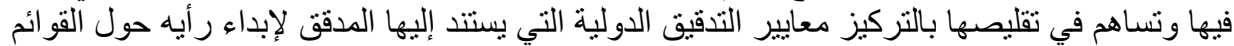

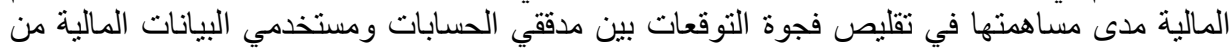

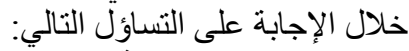

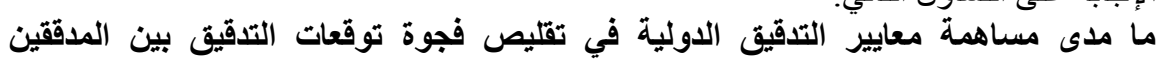
الخارجيين ومستخدمي البيانات المالية؟

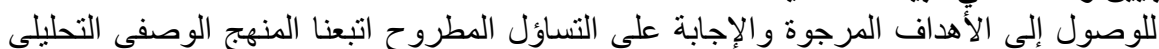

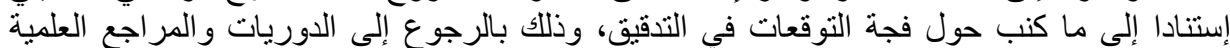

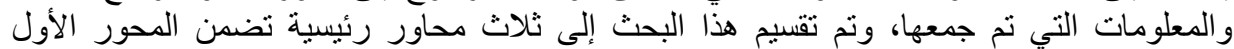

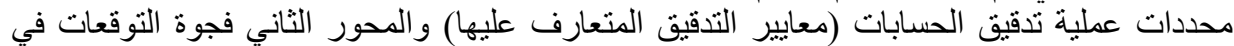

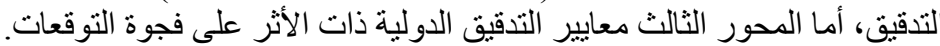

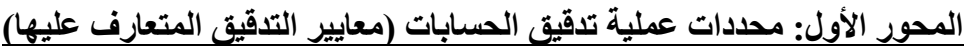

تتمثل معايير التدقيق إرشادات (دليل) عامة لمساعدة الددققين على تنفيذ مهامهم، فهي بمثابة

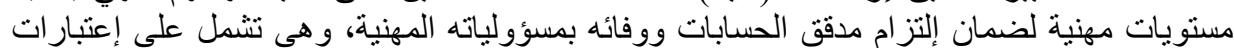

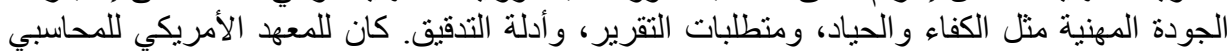

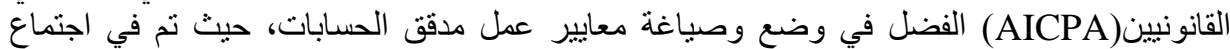

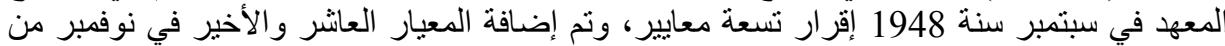
سنة 1949، وصدرت في كتيب سنة 1954(19)نذكر ها في الثكل التالي: 


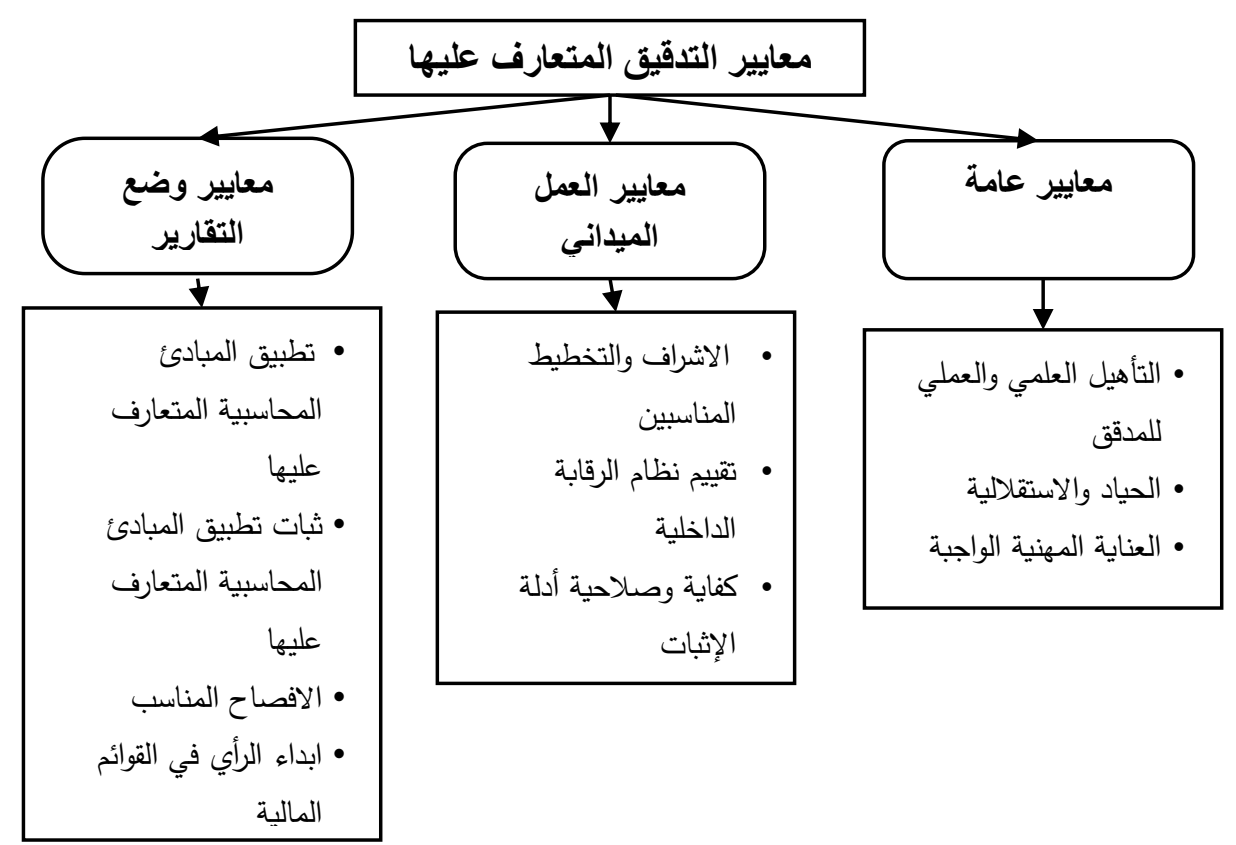

Source : Maire oughran, Auditing for Dummies, Wiley Publishing, Inc, Indianapolis. Indiana. USA. p43

أولا: المعايير العامة: المعايير العامة هي تللك التي تتعلق بالمؤهلات الثخصية للقائم بعملية التدقيق

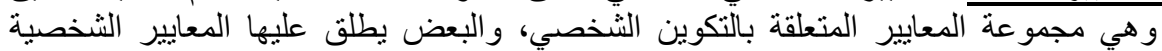
تتمثل في:

التأهيل العلمي (التعليم) والعملي (الخبرة والكفاءة)

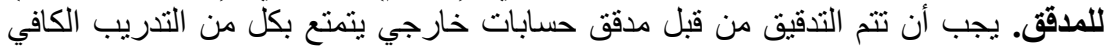

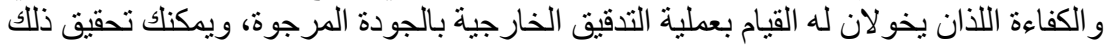
من خلال التعليم وخبرة الناتجة عن الممارسة، وكذا الاستمر ارية في الاطلاع التهاع علة المستجدات الحياد والاستقلالية: غالبا ما بشار إلى الإستقلالية بأنها

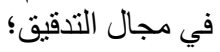

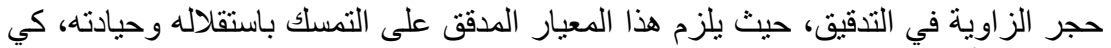

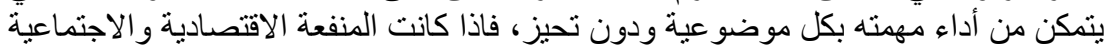

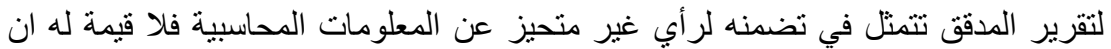

العناية المهنية الواجبة: دائما ما يتوقع الجمهور أن الن النية

تخلى عن عنصر الحياد (2).

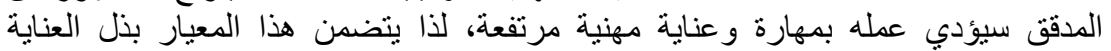

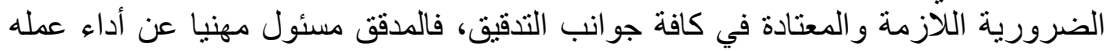


على نحو جاد وحذر، ولتوضيح الفكرة، يشمل بذل العناية المهنية جو انب مثل: اكتمال أوراق

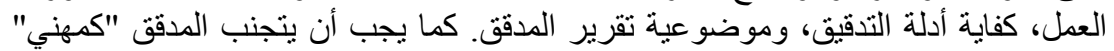

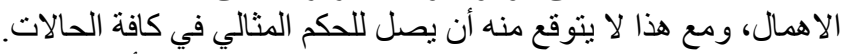

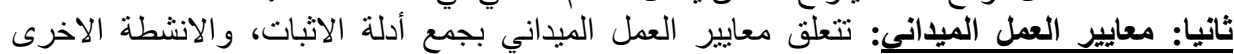
المتعلقة بأداء العمل الميداني وتتحصر في ثلاثئة معايير هي:

التخطيط السليم وتقسيم العمل والإشر اف على المساعدين: أهمية التحقق من أن العمل قد تم

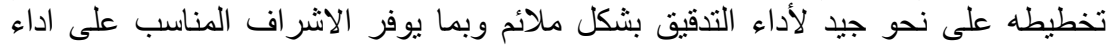

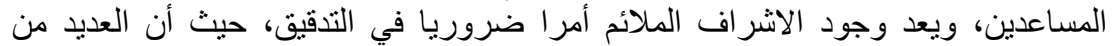

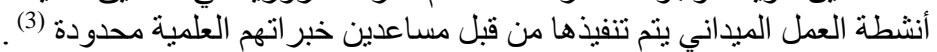

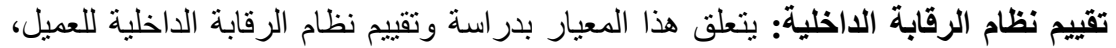

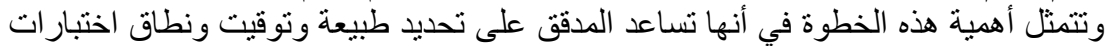

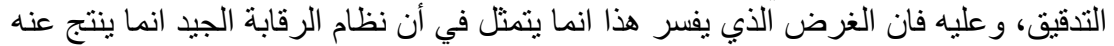
معلومات مالية يمكن الاعتماد عليها.

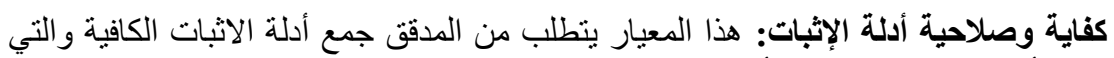

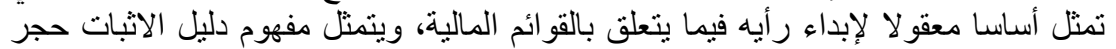

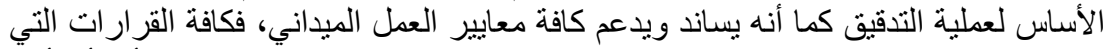

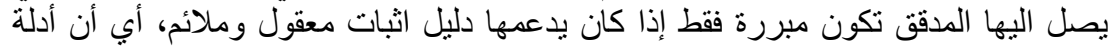

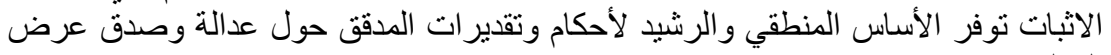

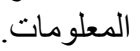

ثاثثا: معايير اعداد التقرير: ان تقرير التدقيق يمثل المنتج المادي الاساسي للمراجعة، فهو يمثل

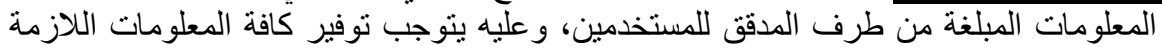

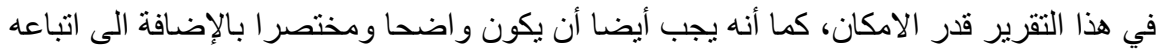
لنموذج مهنة التدقيق، وتحقيق لذلك فقد وضعت النان المعايير التالية:

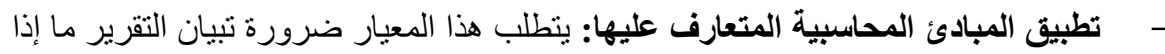

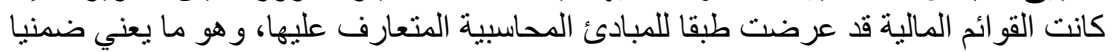

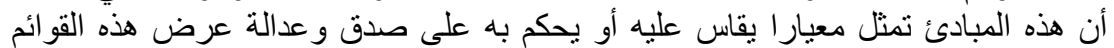

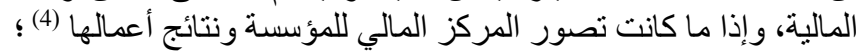

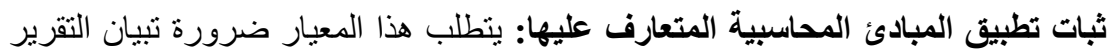

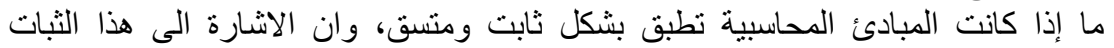

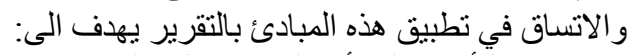
التأكيد على أن المقدرة على المقارنة بين القئ القوائم المالية لا تتأثر بشكل جوهري بالتغير ات في تطبيق المبادئ أو الطرق المقارن المحاسبية؛

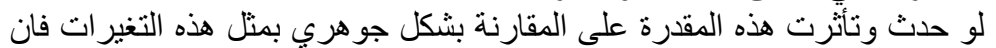

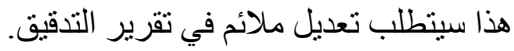

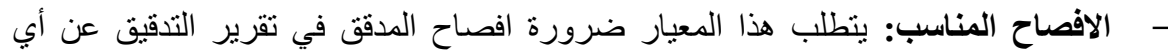

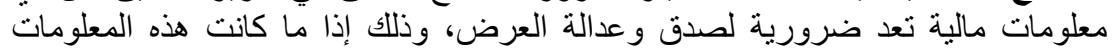

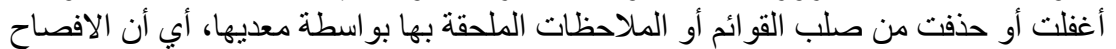

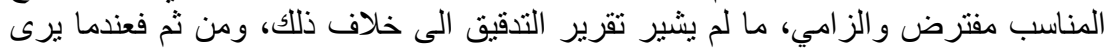


قارئ القو ائم المالية تقرير التدقيق غير متحفظ، فان هذا معناه أن المدقق قد وصل الى قناعة المقاء

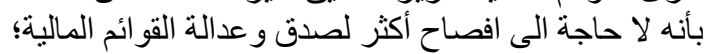

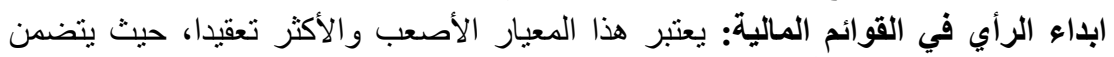

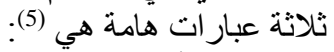

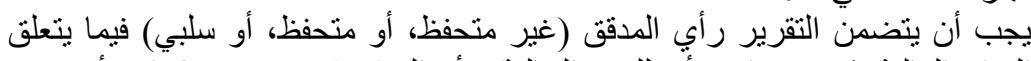

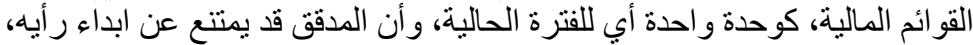

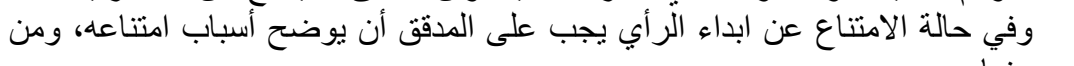

- - تحديد وتقيبيد النطاق بشكل يؤثر جو هريا على مدى فحص المدقق،

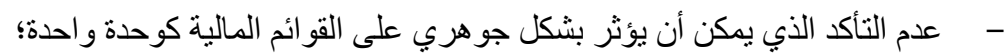

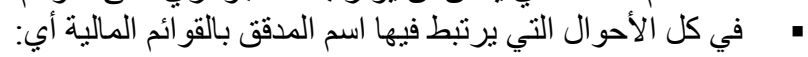

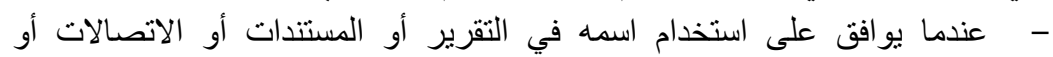
التبليغات المكتوبة التي تتضمن القو ائم المالية؛ - -

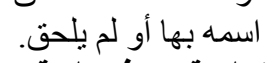

المحور الثانى: فجوة التوقعات في التدقيق

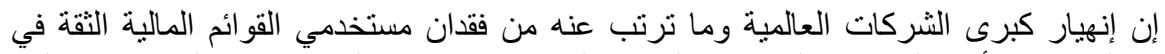

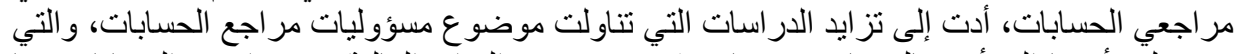

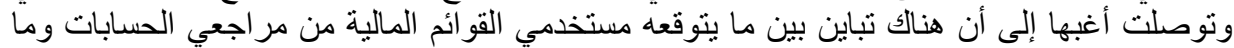

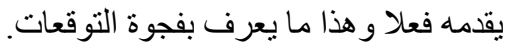

\section{أولا: مفهوم فجوة التوقعات}

أكدت العديد من الدراسات خلال 1970 وجود فجوة توقعات في التدقيق، بين مدققي الحسابات

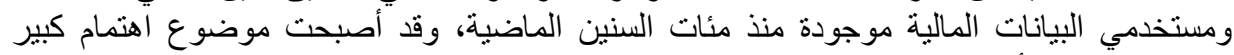

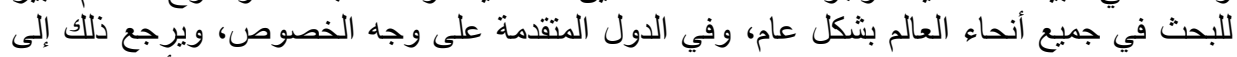

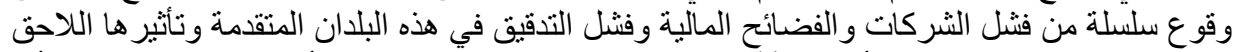

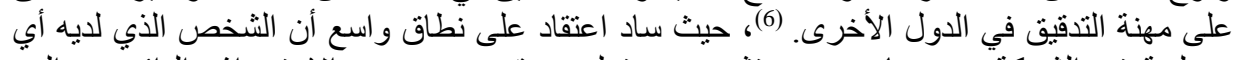

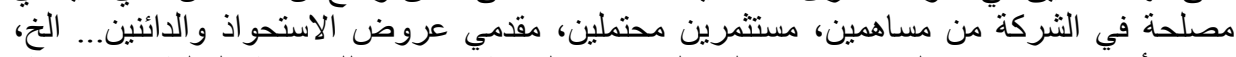

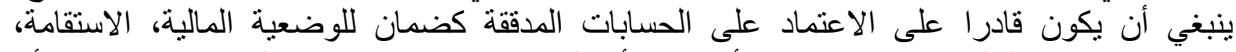

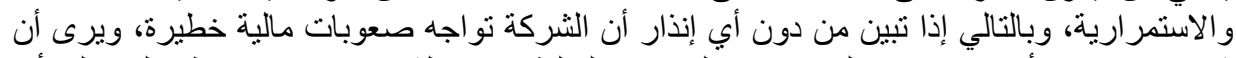

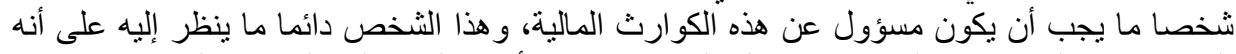

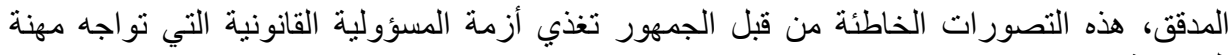

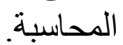

هناك تعريفات مختلفة لفجوة التوقعات في التدقيق وعلى مر السنين نم توسيع مفهومها حيث

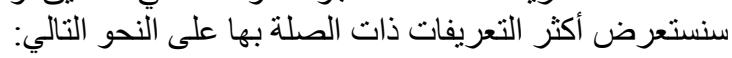


- كان (Liggio) أول من أدخل مصطلح "فجوة التوقعات في التدقيق" لقاموس التدقيق سنة 1974،

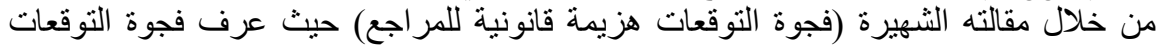

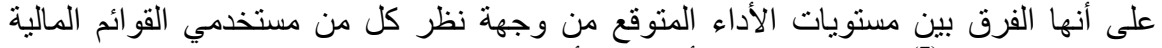

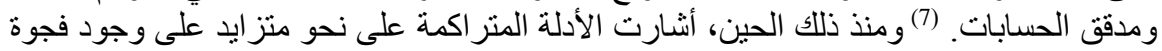

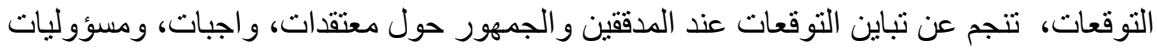

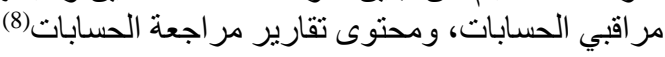

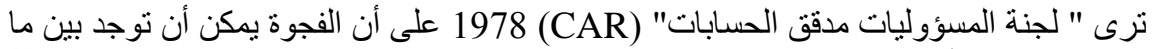

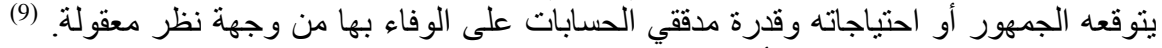

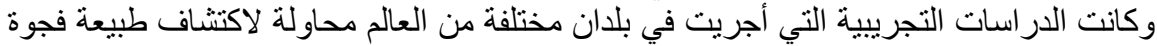

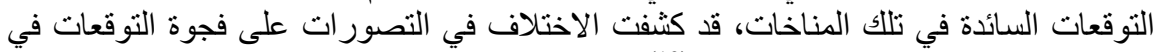

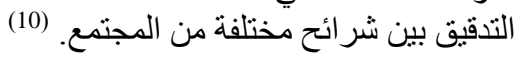
كما ترى (Jennings) أنها الفرق بين ما ينوقعه الجمهور من مهنة مر اجعة الحسابات، وما تمثلك.

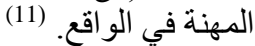
وعليه فقد أجمعت العديد من التعريفات على حدوث اختلاف بين الأداء الفعلي والأداء المتوقع

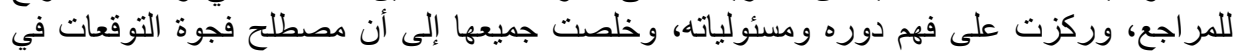

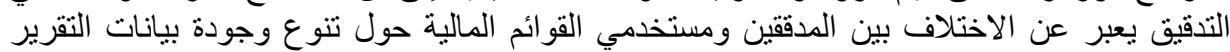

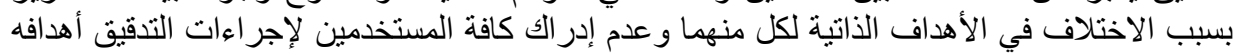

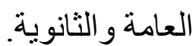

ثانيا: أسباب وجود فجوة توقعات

أكدت العديد من الدر اسات على وجود فجوة التوقعات في التدقيق إلا أن مسببات تلكات الفجوة لم يتم

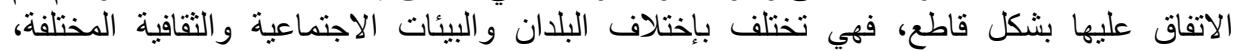

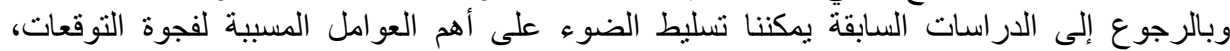

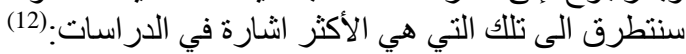
الشكل رقم: أهم العوامل المسببة لفجوة التوقعات 


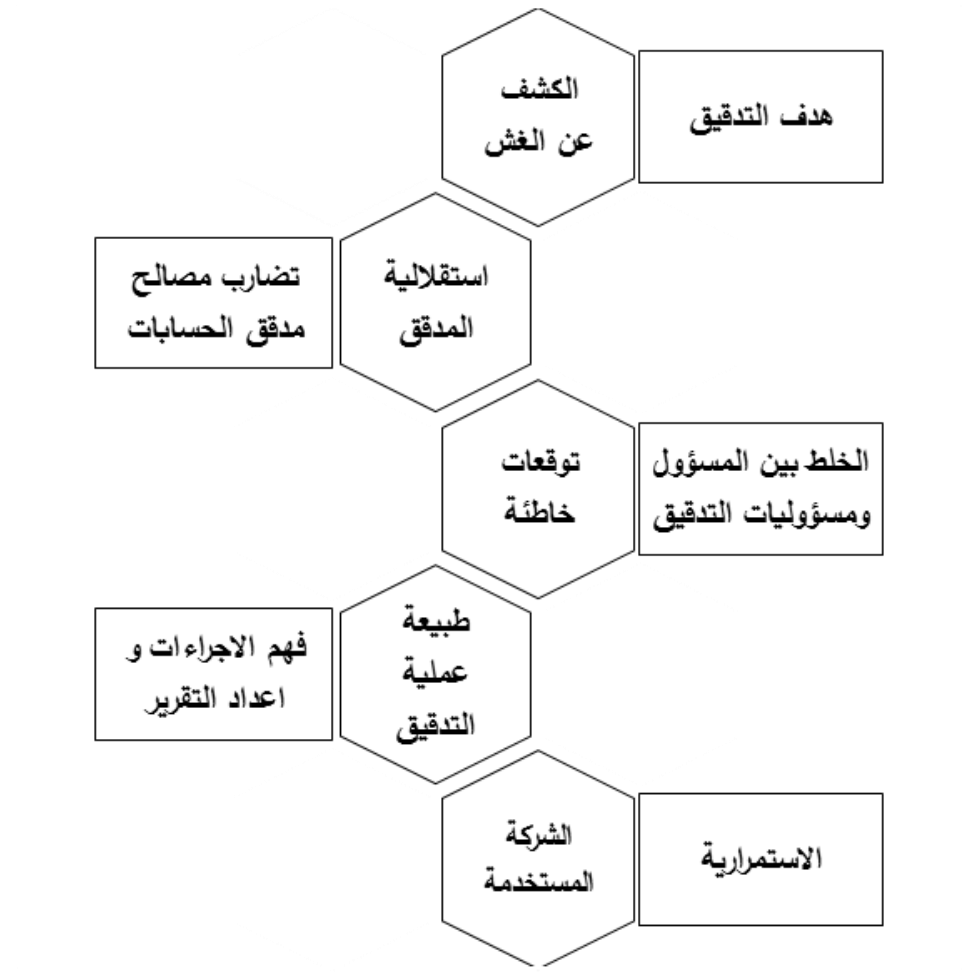

Source: Ramon Saladrigues - Marta Grañó, Audit expectation gap: fraud detection and other factors, Saladrigues: Business Administration Department, University of Lleida, Spain, 2014 , pp :126-129

http://www.accid.org/eamr/downloads/6/6 Audit expectation gap fraud dete ction and other factors.pdf

$$
\text { 1 }
$$

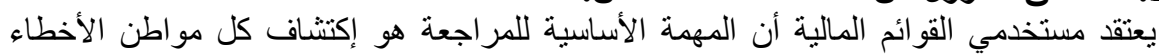

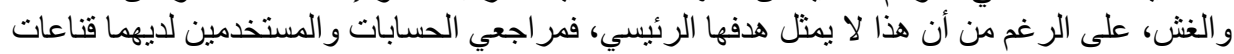

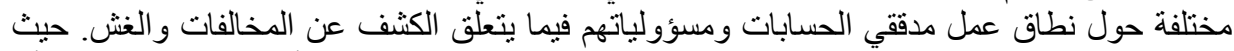

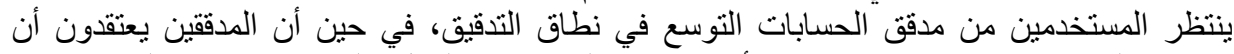

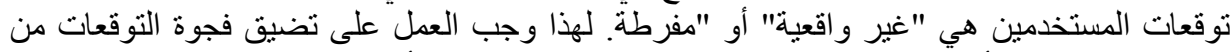

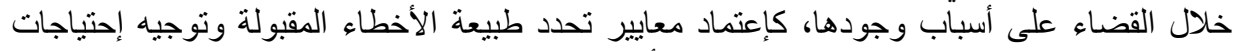

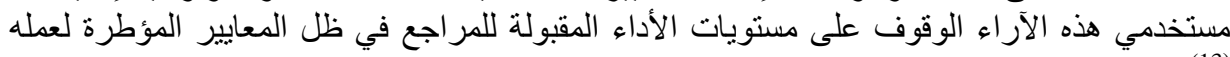


2.

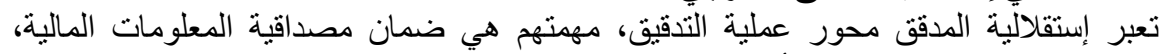

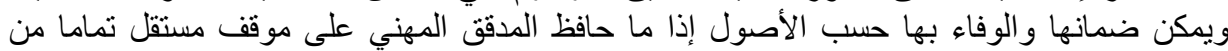

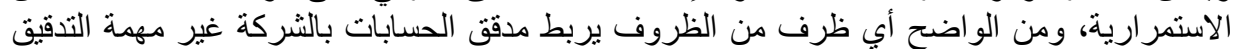

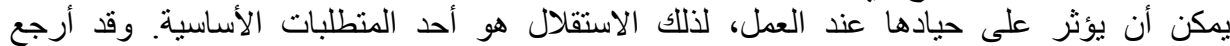
المستخدمين العناصر اليت تؤثر سلبا على إستقلالية المدقق إلى:

$$
\begin{aligned}
& \text { - التتوع في تقديم الخدمات الإستشارية بالموازات إلى خدمة التدقيق إلى عملاء التدقيق؛ }
\end{aligned}
$$

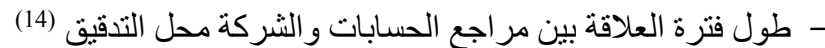

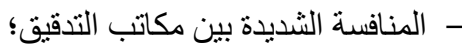

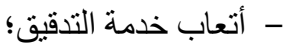

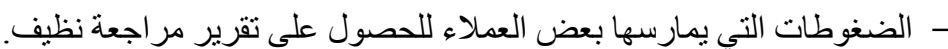

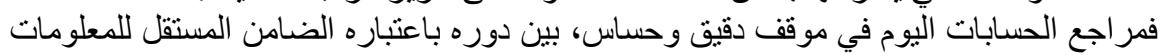
المالية وكذا التز اماته المهنية اتجأه الجهات المستخدمة له

\section{3. عدم التحليد الاقيق لمسؤوليات المدقق ودوره في المجتمع:}

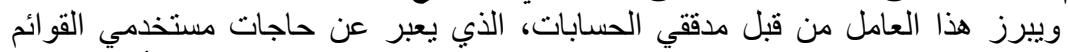

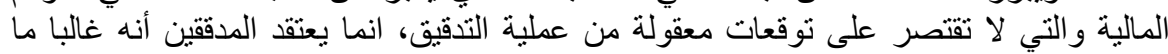

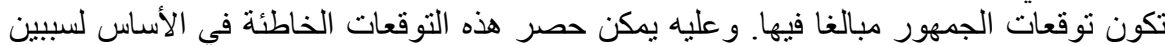

- - بسبب التصور ات المفرطة حول نطاق ومسؤولية مدقق الحسابات: فهناك مثال ينكرر نسبيا

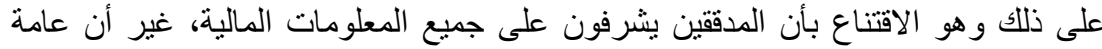

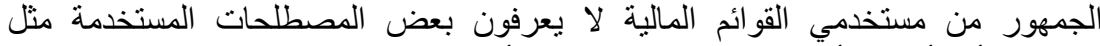

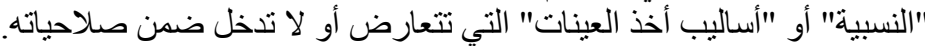

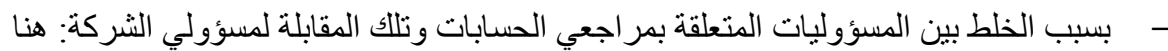

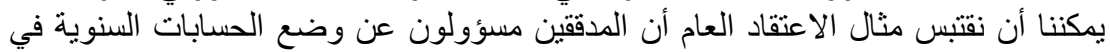

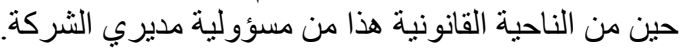

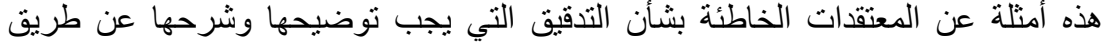
وضع شروط على مستوى يسمح بإعطاء نظرة أوضح عن مهام ومسؤوليات المدققين.

\section{4. صعوبة فهم الطبيعة الفعلية لعملية التدقيق:}

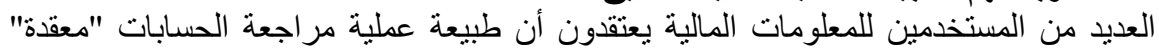

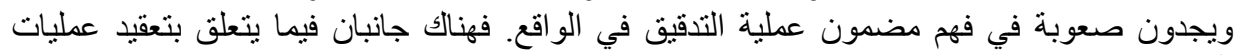

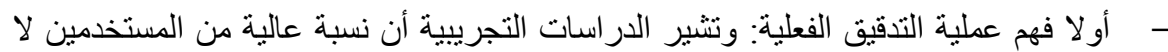

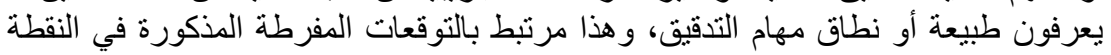

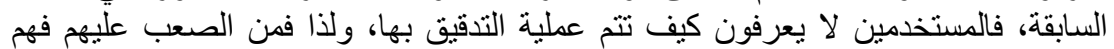

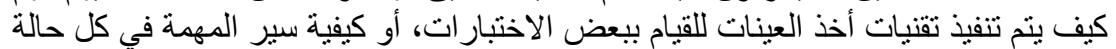




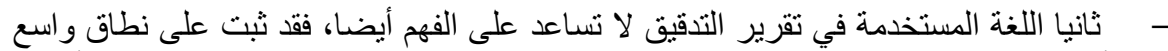

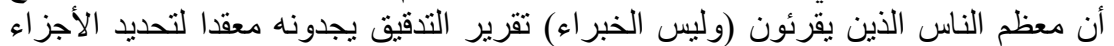

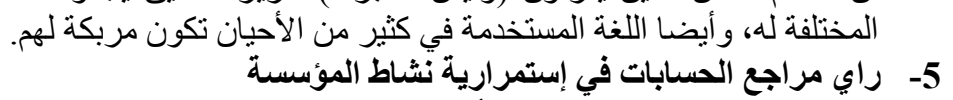

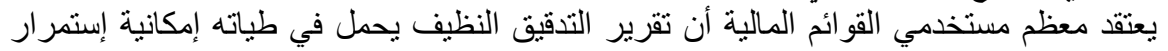

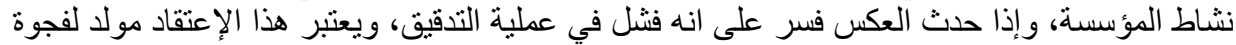

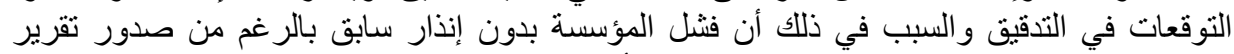

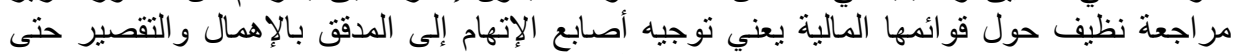

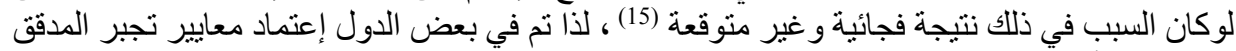

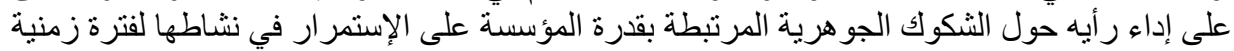

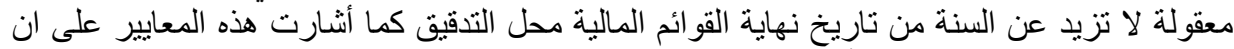
المدقق غير مجبر على التنبؤ بالأحداث المستقبلية للمؤسسة التي تمس قدرتها لتها على الإستهر ارية.

ثالثا: مكونات فجوة التوقعات في التدقيق الخارجية

من خلال ما تم استعر اضه، يمكن التأكيد على وجود فجوة توقعات في التدقيق، تتكون من عنصرين رئيسيين سيتم استعر اضهما كالأتي:

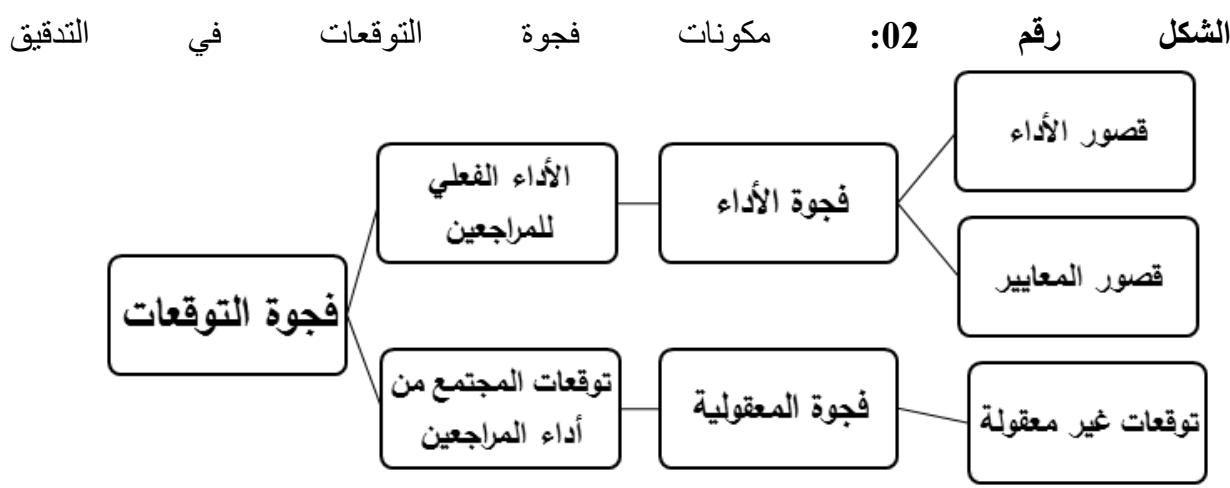

Source: Brenda Porter, The audit expectation-performance gap and users' understanding of, and desired improvements to, the auditor's report, School of Business and Economics Exeter University, United Kingdom, 2009, $\mathrm{P}$

http://www.ifac.org/system/files/downloads/Porter_et_al_Final_Report_Combi $\underline{\text { ned.pdf }}$ 
هذه الفجوة تنتأ نتيجة التباين بين ما يتوقع المجتمع (المستفيدين من خدمات التدقيق) من مر اقبي

الحسابات إنجازه، و بين ما يستطيع مر اقب الحسابات إنجازه بصورة التبان معقولة.

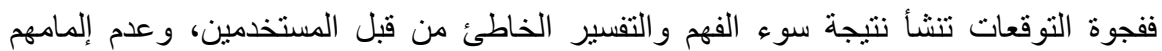

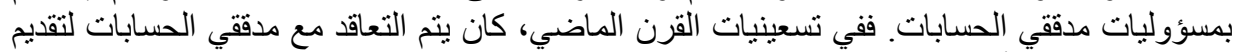

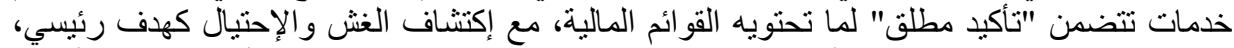

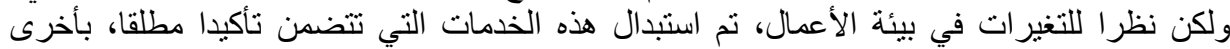

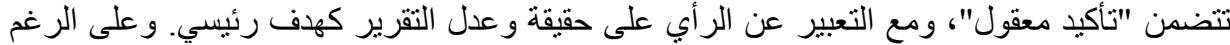

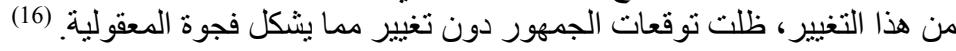

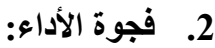

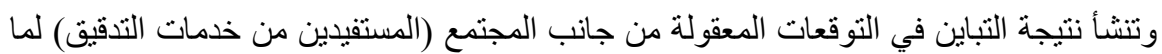

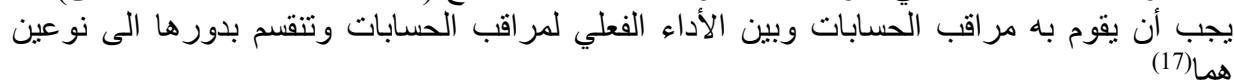

\section{أ. فجوة المعايير الناقصة:}

هنآك فجوة بين الواجبات التي بمكن نوقعها بصورة معقولة من و المدققين، و الو اجبات

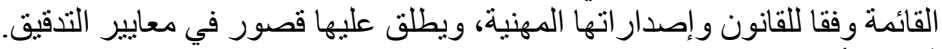

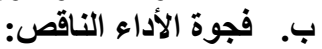

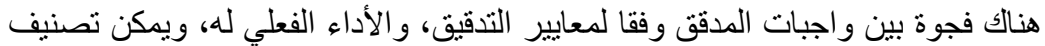

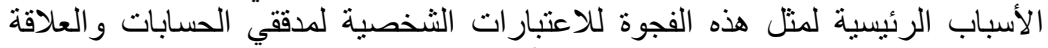

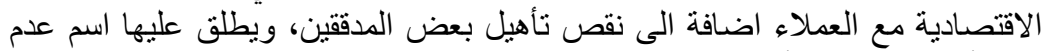
كفاية أو قصور في الأداء.

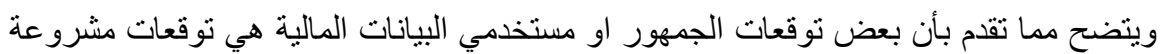

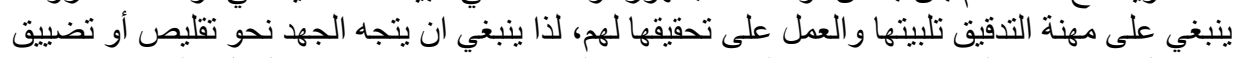

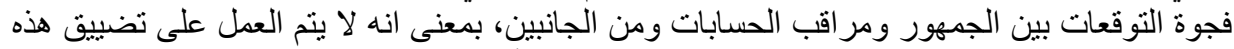

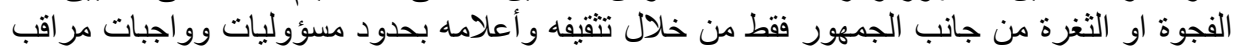

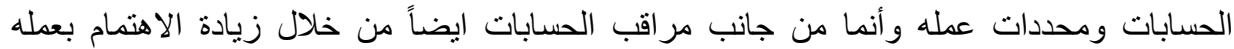

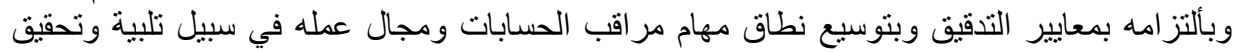
الاحتياجات المشرو عة لمستخدمي البيانات المالية المدققة.

\section{المحور الثالث: معاييز التدقيق الدولية ذات الأثر على فجوة التوقعات}

\section{أولا: المعيار رقم (200) الأهداف العامة للمراجع المستقل وإجراءات التدقيق، طبقا لمعايير التدقيق}

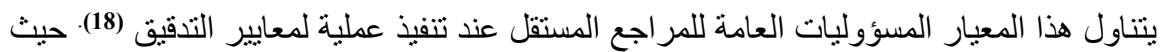

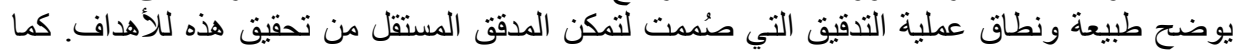

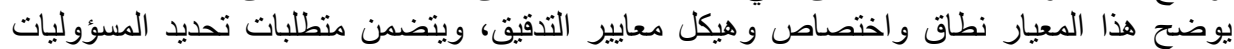

العامة للمر اجع المستقل و المعمول بها في كافة عمليات التدقيق، بما في ذللك الإلتز ام بمعايير التدقيق.

ويفرض هذا المعيار إلتزام المدقق بقواعد السلوك المهني للمحاسبين وهي: النزاهة،

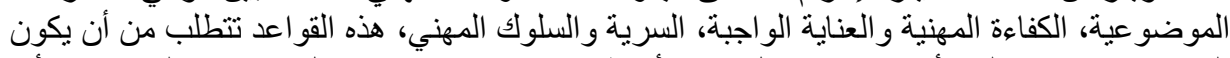

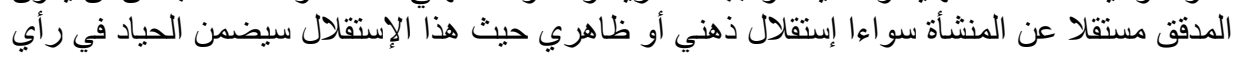


المدقق كما يعزز الإستقلال قدرة المدقق على التصرف بنزاهة وموضوعية بما يحفظ نزعة الثكك

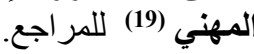

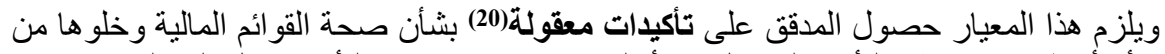

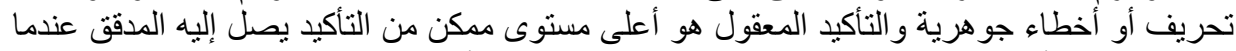

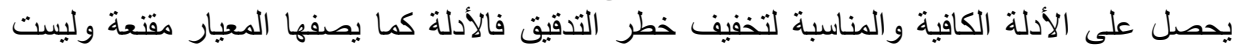

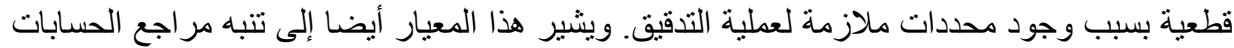

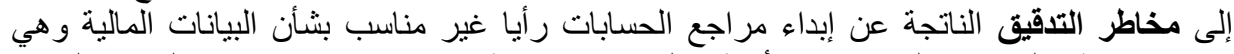

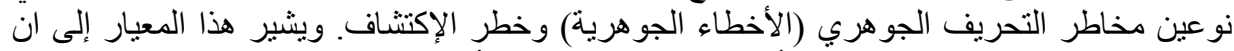

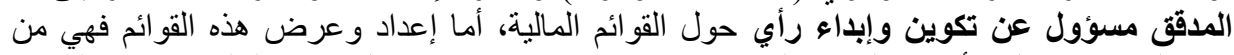

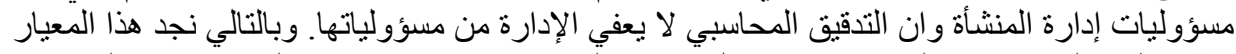

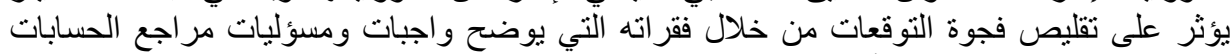

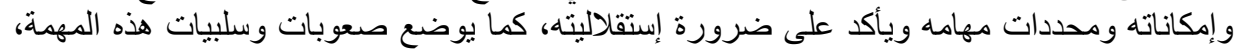
ويفصل في المسؤوليات بين المدقق و الإدارة.

ثثانيا: المعيار رقم (240) مسؤوليات المدقق إتجاه الغش عند مراجعة القو ائم المالية

يتناول هذا المعيار مسؤوليات المدقق عن الغش(21) ، وتوضيح الفرق بين هذا الأخير و الخطأ حتى والثي

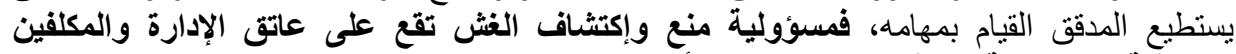

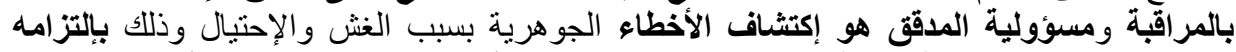

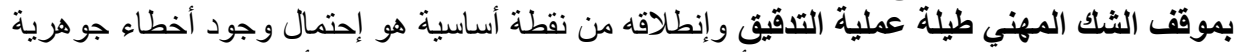

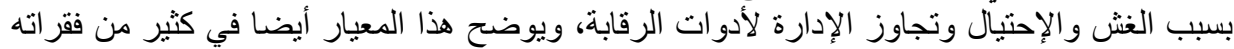
مختلف حالات مخاطر الغش و الإحتيال كيفية تعامل مر اجع الحسابات الأن في كل حالة.

إذن فهذا المعيار يعمل هو الأخر على تقليص فجوة نوقعات التدقيق من خلال توضيح واجبات

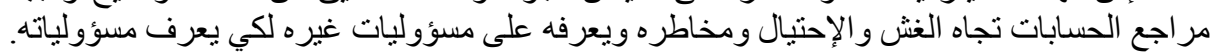

ثالثا: المعيار رقم (250) مر اعاة الأنظمة و اللوائح عند مراجعة القوائم المالية

إن الغرض من هذا المعيار الدولي للتنقيق هو وضع معايير وتوفير ارشادات تتعلق بمسؤولية الإنية

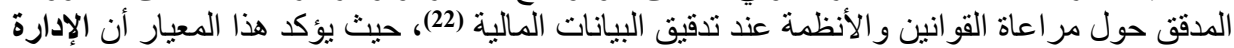

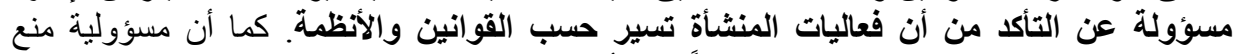

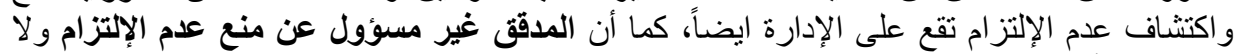

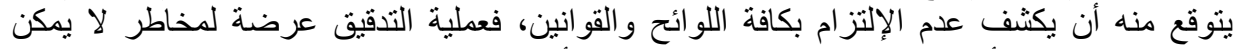

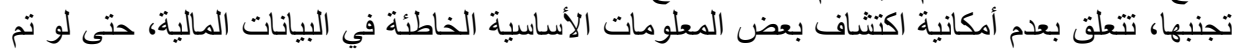

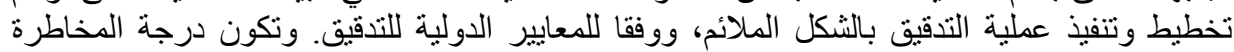

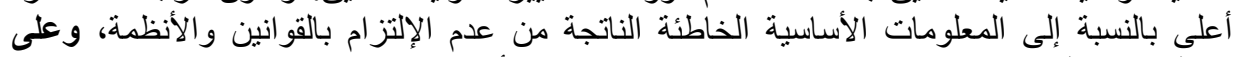

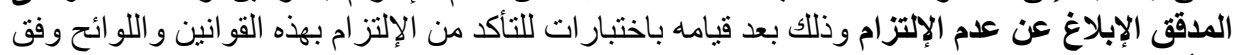

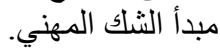

رابعا: المعيار رقم (400) تقاير المخاطر والرقابة الداخلية 
إن الغرض من هذا المعيار الدولي للتدقيق هو توفير إرشادات للمدقق تساعده في فهم النظام

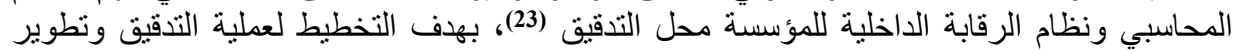

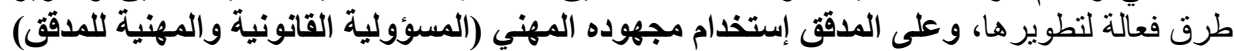

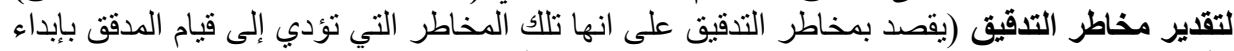

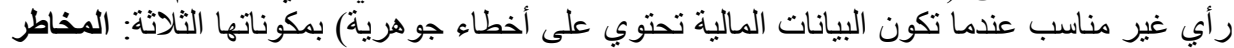

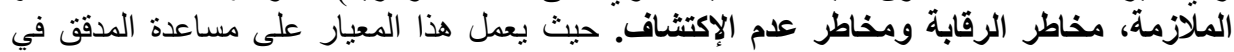
تقدير مخاطر التدقيق مما يساهم في تقليص فجوة التوقية التحات ويزيد من ثقة الجمهور في مخرجات عملية

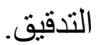

خامسا: المعيار رقم (500) أدلة الإثبات

إن الغرض من هذا المعيار الدولي هو توفير إرشادات للمدقق حول كمية ونوعية (24)أدلة الإثبات

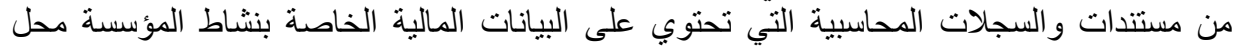

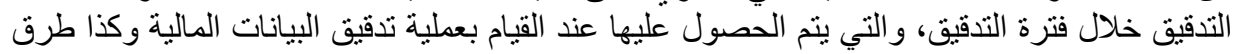

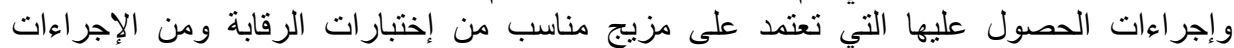

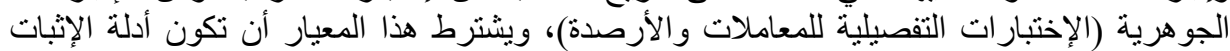

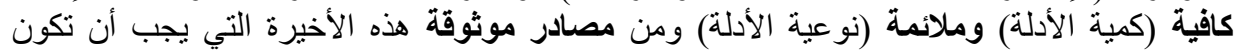

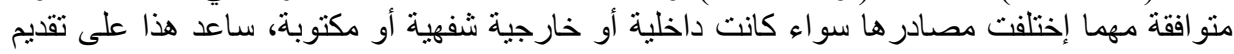

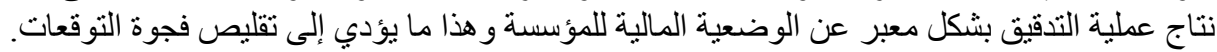

\section{سادسا: المعيار رقح (570) الإستمرارية}

يساعد تقرير المدقق في إضفاء الثقة على البيانات المالية ومع ذللك فإن تقريره لا يعتبر ضمانة إندانة

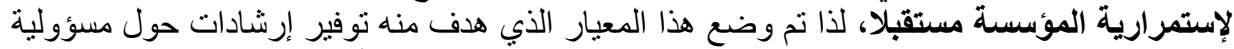

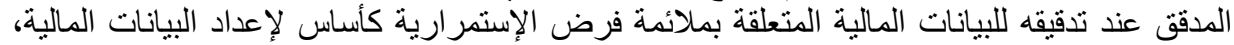

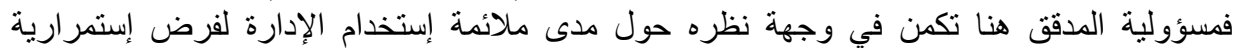

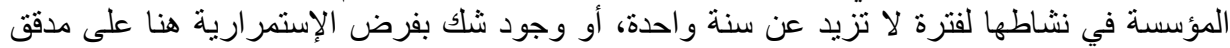

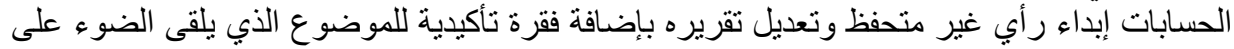

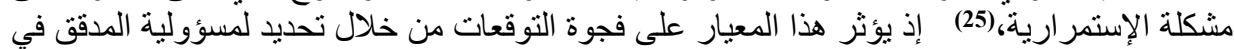

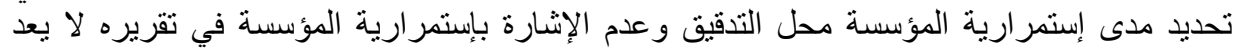
ضمانا لقدرة المؤسسة على الإستمر ار. (26) التصنة

ثامنا: المعيار رقح (580) الإقرارات الإدارية

الغرض من هذا المعيار هو وضع معايير وتوفير إرشادات حول إستخدام إقرارات الإدراة

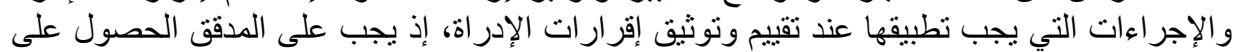

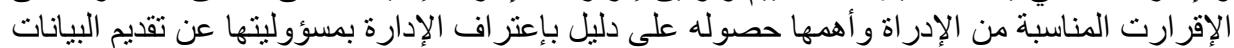

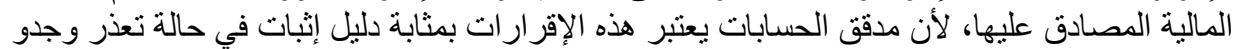

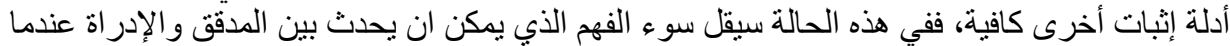

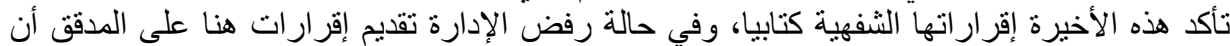

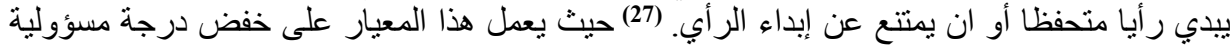
المدقق تجاه مستخدمي التقارير المالية. 


\section{تاسعا: المعيار رقق (700) تقرير المدقق حول البيانات المالية}

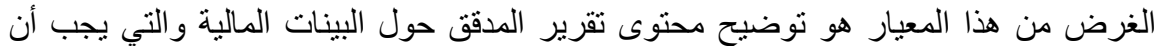

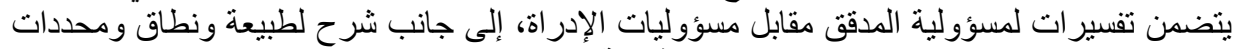

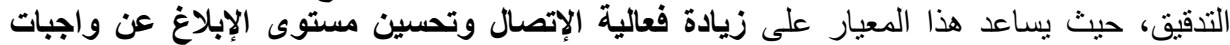

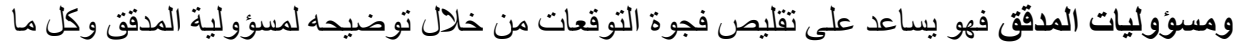
يتعلق بشكل التقرير وفقر اته ومحتو ياته. (28)

الخلاصة:

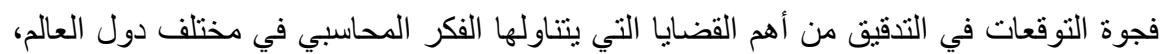

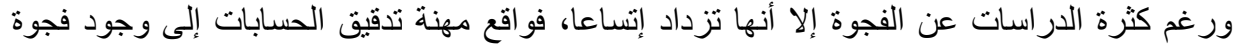

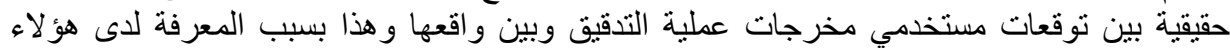

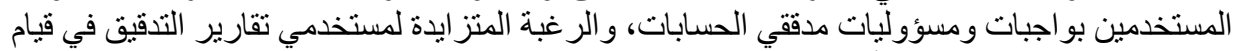

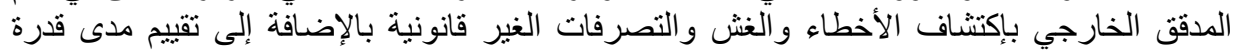

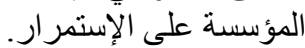

تعمل معايير التدقيق الدولية على تقليص فجوة التوقعات من خلال توضيح واجبات ومسؤوليات

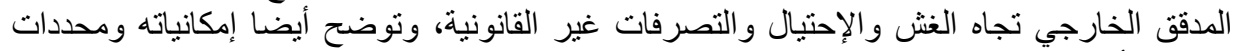

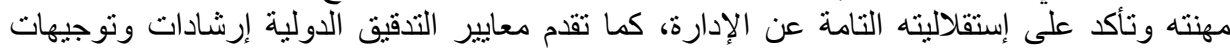

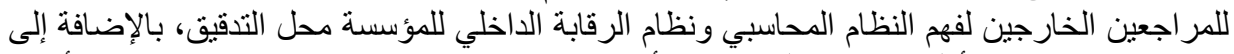

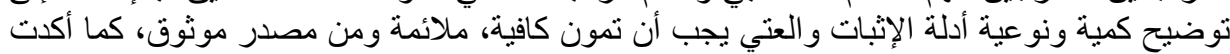

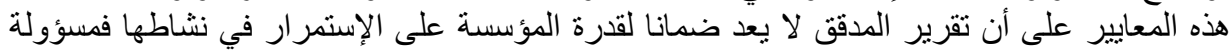
الددقق الخارجي هي نوضيح وجهة نظره حول مدى ملائمة إستخدام الإدارة لفرض الإنئ الإستمر ارية

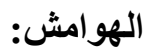

1 محمد السيد ناغي، المراجعة (إطار النظرية والممارسة)، ج2، مكتبة الجلاء الجديدة للنشر، المنصورة، مصر، 1992، ص:37.

2 وليم توماس، المراجعة بين النظرية والتطبيق، دار المريخ، الرياض، السعودية، 1989، ص ص ص: $.56-55$

$$
3 \text { ألفين أرينز، جيمس لوبك، المراجعة مدخل ج 1، دار المريخ، الرياض، السعودية، 2009، }
$$

4 Maire Loughran, Auditing for Dummies, Wiley Publishing, Inc, Indianapolis, Indiana, USA, p44

$$
5 \text { وليم توماس، مرجع سبق ذكره، ص ص: 58-65. }
$$

6 Mahdi Salehi, Audit expectation gap: Concept, nature and trace, African Journal of Business Management Vol. 5(21), 23 September, 2011, p 80-83 
http://citeseerx.ist.psu.edu/viewdoc/download?doi=10.1.1.690.2090\&rep= rep1\&type=pdf

7 Chinwuba Okafor - John I Otalor, Op Cit,, p: 44

8 Hian Chye Koh and E-Sah Woo, The expectation gap in auditing,

Managerial Auditing Journal, 13/3 [1998], Singapore, p: 147

9 Ramon Saladrigues - Marta Grañó, Audit expectation gap: fraud detection and other factors, Saladrigues: Business Administration Department, University of Lleida, Spain, 2014, p:124

10 Chinwuba Okafor - John I Otalor, Narrowing the Expectation Gap in Auditing: The Role of the

Auditing Profession, Research Journal of Finance and Accounting (online), Vol.4, No.2, 2013, p: 44

11 Hian Chye Koh and E-Sah Woo, Op Cit, p: 147

12 Ramon Saladrigues - Marta Grañó, Audit expectation gap: fraud detection and other factors, Saladrigues: Business Administration Department, University of Lleida, Spain, 2014 , pp: 126-129

$$
\begin{aligned}
& 13 \text { مسعود صديقي: ص: } 149 \\
& 14 \text { فيحاء عبد الله بعقوب وآخرون، أثر حوكمة الثركات على تضيق فجوة التوقعات في بيئة العمل }
\end{aligned}
$$

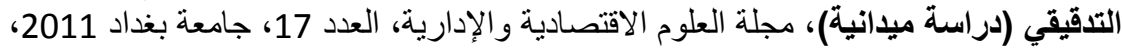

$$
\begin{aligned}
& \text { ص: } 330 \text { ص }
\end{aligned}
$$

http://www.iasj.net/iasj?func=fulltext\&aId=3236

$$
\begin{aligned}
& 15 \text { جورج دانيال غالي، تطوير مهنة المراجعة لمواجهة المشكلات المعاصرة وتحديات الألفية }
\end{aligned}
$$

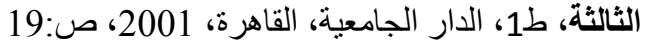

16 Austine O. Enofe et ALL, Audit Reasonableness Expectations Gap:

Users' Perception in Nigeria, International Journal of Business and Social Research (IJBSR), Volume -3, No.-3, March 2013, p: 158

17 Mahdi Salehi, Op Cit, pp: 82-83

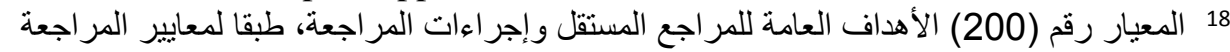
http://www.ifac.org/system/files/downloads/a008-2010-iaasb-handbook-isa200.pdf

$$
\begin{aligned}
& 19 \text { الثُك المهني: نزعة تتضمن عقلا متسائلا، و إلتز ام الحذر بشأن الحالات التي تثير إلى إمكانية }
\end{aligned}
$$

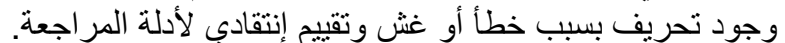

$$
\begin{aligned}
& 20 \text { التأكيد المعقول: في بيئة مر اجعة القو ائم المالية يقصد به مستوى مرتفع من التأكيد ولكنه غير }
\end{aligned}
$$

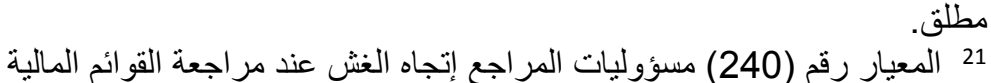

http://www.ifac.org/system/files/downloads/a012-2010-iaasb-handbook-isa240.pdf

$$
22 \text { المعيار رقم (250) مر اعات الأنظمة و اللو ائح عند مر اجعة القو ائم المالية }
$$

http://www.socpa.org.sa/getattachment/Socpa/TechnicalResources/Standards-Projects/250.pdf.aspx 
23 المعيار رقم (400) تقدير المخاطر و الرقابة الداخلية http://ia902707.us.archive.org/22/items/isas12000/400.PDF 24 المعيار رقم (500) أدلة الإثبات http://ia600304.us.archive.org/0/items/Isas22000/500.PDF 25 المعيار رقم (570) الإستمر ارية http://ia800304.us.archive.org/0/items/Isas22000/570.PDF

26 عمر علي كامل الدوري، دور معايير التدقيق فب تقليص فجوة التوقع، مجلة المنصورة، العدد 14،

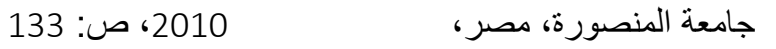
27 المعيار رقم (580) الإقرارات الإدارية http://ia800304.us.archive.org/0/items/Isas22000/580.PDF 28 محمد مروان الصبوح، دور معايير التدقيق الدولية في تقليص فجوة نوقعات التدقيق (دراسة ميدانية

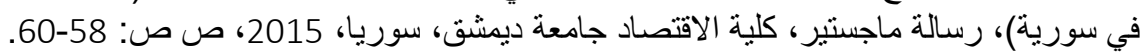

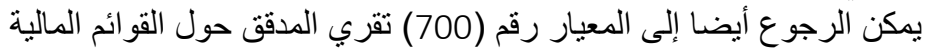
http://ia801407.us.archive.org/11/items/Isas32000/700.PDF 